\title{
Overview of Lumbosacral MRI Findings in Jos University Teaching Hospital
}

\author{
Salaam $\mathrm{AJ}^{1^{*}}$, Danjem $\mathrm{SM}^{1}$, Salaam $\mathrm{AA}^{2}$, Ogbu $\mathrm{AE}^{1}$ \\ ${ }^{\prime}$ Department of Radiology and ${ }^{2}$ Department of Family Medicine, Jos University Teaching Hospital.
}

*Corresponding Author: Dr. Salaam AJ. Department of Radiology, Jos University Teaching Hospital. E-mail: adeku2s@gmail.com

\begin{abstract}
Lumbosacral conditions are common disorders involving the soft tissues and bones of the low back. They may be due to underlying pathologies such as slipped disc, low back pain, TB spine, paraplegia, spinal tumour, degenerative disc disease, lumbosacral spondylosis, cord compression syndrome, traumatic spinal cord injury, caudaequina or fractures of any part of the vertebrae below $\mathrm{T}_{12}$ down to the gluteal fold. Degenerative disc disease, lumbar spondylosis, degenerative disc disease and exit nerve root compression are common findings in the MRI scan of patients with lumbosacral conditions. The MRI scan of patients with lumbosacral conditions seen between 2016 and 2017 were evaluated for the study. The features assessed were degenerative disc diseases, lumbar spondylosis, degenerative disc disease with exit nerve root compression, spinal cord contusion/injury, Pott's disease and lumbar spondylolisthesis. myelitis, lumbar spondylosis with degenerative disc disease, as well as lumbar fracture were also assessed. A total of 233 patients with lumbosacral pathologies were included in this study. There were $132(56.7 \%)$ males and $101(43.3 \%)$ females. Of all the patients with radiculopathies, patients with low back pain as the major indication constituted $23.2 \%$, followed by those with lumbosacral spondylosis (19.3\%), paraplegia (15.5\%) and slipped disc (13.7\%), while patients with caudaequina and spinal tumour represented $2.6 \%$ and $1.7 \%$ respectively. Degenerative disc disease was the most common finding representing 38.2\% patients, followed by lumbar spondylosis (14.6\%) and degenerative disc disease with exit nerve root compression (14.2\%). Lumbar fracture was the least common finding in 1.3\% of patients with lumbosacral conditions. MRI can be used to identify pathologies of lumbosacral tissues in a non-invasive manner. There was a high prevalence of radiculopathies in the lumbosacral spine of patients.
\end{abstract}

Keywords: Degenerative disc disease, Low back pain, Lumbosacral spondylosis, Paraplegia, Slipped disc.

\section{INTRODUCTION}

$\mathrm{L}$ umbosacral conditions are interrelated and often leads to low back pain, which varies from a dull, heavy sensation to sharp agonizing spasm. The cause of the pain is equally variable. For example, joint instability can lead to disc degeneration, which in turn can put pressure on the nerve roots, etc. ${ }^{1}$ Slipped disc is a vertebral disc that has broken down to the point where the inner material, called the nucleuspulposus, has seeped through the wall of the vertebral disc, causing pain in the surrounding structures or nerves. A slipped disc can occur in the lower back, the neck and, rarely, in the midback. $^{2}$ 
Low back pain or lumbago, which may or may not occur with sciatica, is a common disorder involving the soft tissues and bones of the lower back. The "low back pain" has been defined as pain limited to the region between the lower margins of the twelfth ribs and the lower gluteal fold. ${ }^{3}$ Low back pain may be classified by duration as acute (pain lasting less than 2 weeks), sub-acute (pain lasting between 2 weeks to 3 months) and chronic (pain lasting more than 3 months). ${ }^{4}$ It has also been classified as specific and non-specific. The specific low back pain is defined as low back pain attributable to a recognizable, known specific pathology, while nonspecific low back pain is defined as low back pain not attributable to a recognizable, known specific pathology. The non-specific low back pain constitutes about $90-95 \%$ of all low back pain cases.

TB spine, also known as tuberculous spondylitis or Pott's disease, refers to vertebrate body and intervertebral disc involvement with tuberculosis. The spine is the most frequent location of musculoskeletal TB and commonly related symptoms are back pain and lower limb weakness/ paraplegia. ${ }^{6}$

Paraplegia is a spinal cord injury that paralyses the lower limbs. It is a result of severe damage to the spinal cord and the nervous system. Paraplegia mainly affects the trunk, legs and the pelvic region, resulting in loss of movement. It can be caused by accident, motor neuron disease, tumor or blood clot within the spinal cord. They are two main categories: complete and incomplete. Complete paraplegia is witnessed when the injury affects the neurological level and its hinders the movement of limbs, where as in case of incomplete paraplegia, some of the limbs are still moving. ${ }^{7}$

Spinal tumour is an abnormal mass of tissue within or surrounding the spinal cord and/ or spinal column. These cells grow and multiply uncontrollably, seemingly unchecked by the mechanisms that control normal cells. Spinal tumour can be benign (non-cancerous) or malignant (cancerous). Primary tumours originate in the spine or spinal cord while metastatic or secondary tumours result from cancer spreading from another site to the spine. Spinal tumours may be referred to by the region of spine in which they occur. These basic areas are cervical, thoracic, lumbar and sacrum. Additionally, they are also classified by their location in the spine into three major groups: intradural -extramedullary, intramedullary and extradural. $^{8}$

Lumbosacral degenerative disc disease refers to a syndrome in which a compromised disc causes low back pain. It is related to a combination of bio-mechanical stresses and genetic predisposition which alter the metabolic and structural integrity of the intervertebral disc. These changes, in turn, modify the ability of the intervertebral disc to sustain and transmit forces and, subsequently, compensate for these alterations in a variety of ways. This leads to billions of dollars in health care services and lost productivity every year due to associated morbidity from these conditions. Degenerative changes includes any of the following: desiccation, fibrosis, narrowing of the disc space, diffuse bulging of the annulus beyond the disc space, annular fissures, mucinous degeneration of the annulus, intra-discal gas, osteophytes of the vertebral apophyses, inflammatory changes and sclerosis of the end plates. ${ }^{9}$

Lumbosacral spondylosis, also referred to as lumbar spondylosis, is a unilateral or bilateral defect of the pars interarticularis that affects one or more of the lumbar vertebrae. Numerous hypothesis have been proposed on the etiology of lumbosacral spondylosis. They include: separate ossification centre, fracture during post natal life, stress fracture, increased lumbar lordosis, impingement of the articular process on the pars inter-articularis, weakness of supporting structures, pathologic changes in the pars articularis and dysplasia of the pars interarticularis. ${ }^{10}$

Spinal cord compression syndrome develops when the spinal cord is compressed by bone fragments from a vertebral fracture, a tumour, abscess, ruptured intervertebral disc or other lesion. Spinal cord compression can occur anywhere from the neck down to the lower spine and cause symptoms, such as numbness, pains and weakness. Depending on the cause of compression, symptoms may develop suddenly or gradually, and they may require anything from supportive care to emergency surgery. ${ }^{11}$ Traumatic spinal cord injury (SCI) is an insult to the spinal cord resulting in a change, either temporary or permanent, in the cord's normal motor, sensory or autonomic function. ${ }^{12}$ Traumatic SCI may stem from a sudden traumatic blow to the spine that fractures, dislocates, crushes or compresses one or more vertebrae. ${ }^{13}$ They can be complete or incomplete. Traumatic SCI can be categorized into primary and secondary phases. The primary SCI is the result of physical forces of the initial traumatic events and is often the most important determinant of injury severity. Physical forces involved can include compression, shearing, laceration, and acute stretch. After the primary injury event, a cascade of secondary injury events is initiated 
which serves to expand the zone of neural tissue injury and exacerbate neurological deficits. Secondary SCI is a delayed and progressive tissue injury following the primary SCI. ${ }^{14}$ Cauda equina syndrome (CES) is a rare disorder in which there is a compression of the spinal nerve roots. CES affects a bundle of nerve roots called caudaequina. These nerves are located at the lower end of the spinal cord in the lumbosacral spine. $^{15}$

MRI has the potential to identity pathologies of these tissues in the lumbosacral spinein a non-invasive manner. The role of MRI in lumbosacral conditions could be to exclude patients without a target condition, to spare invasive treatment or to identify as many patients as possible where delayed treatment would result in worse patient outcome. This current study was aimed at investigating the pathological changes in the lumbosacral spinal tissue identified on MRI which could be responsible for lumbosacral conditions.

\section{MATERIALS AND METHODS}

\section{Study Location}

This was a retrospective cross-sectional study conducted in a teaching hospital, which is a tertiary health institution, in North-Central Nigeria. The patients were referred from the orthopaedic clinic. Majority of the residents around the study area, are engaged in mining, farming and other agricultural activities. The MRI of all cases of lumbosacral conditions carried out between 2016 and 2017 were evaluated to identify cases suitable for the study. The study criteria was met by 233 patients who were then included in the study. The exclusion criteria were as follows: history of previous lumbosacral surgery, patients with profound scoliosis or kyphosis of the lumbosacral spine, history of spinal laser interventions and patients with osteoarthrosis of the knee and hip. Patients with ankylosing spondylitis and those with incomplete records were also excluded.

Informed consent from patients was not required as this was a retrospective study.

\section{Data Collection and Image Interpretation:}

MRI examination was performed using 0.2 tesla MRI machine (Magnaton concerto, Siemens medical system, $\mathrm{DEU})$. All the patients were placed supine with straight leg in a psoas tight position to imitate the lumbar lordosis seen in erect position. A rectangular flat surface coil was used. The imaging protocol consisted of one coronal localizer with repetition time and echo time (TR/TE) of $25 / 10 \mathrm{msec}$, sagittal T1 weighted spin echo, (TR/TE) of 412/19 msec, and a sagittal view with a TR/TE (dual echo sequence of 2500$4000 / 20$ and $127 \mathrm{msec}$ ). The axial image were performed to cover the last three lumber intervertebral disc. If slipped disc was present at higher lumbar levels, relevant supplementing axial series were performed. Gradient nulling was employed to minimize motion artefacts. For all the sequences, the slice thickness was $3 \mathrm{~mm}$. The images were assessed by a diagnostic radiologists. The features assessed were degenerative disc disease, lumbar spondylosis, degenerative disc disease with exit nerve root, Pott's disease and spinal cord contusion. Lumber spondylolisthesis, nerve root disease, lumbar spondylosis with degenerative disc disease and myelitis were also assessed.

\section{Statistical Analysis}

The data were analysed using statistical package SPSS version 21. The prevalence of changes in the above mentioned features were tabulated. The number of affected variables in the tables can be single or multiple, hence when added up were usually more than the study population of 233 .

\section{RESULTS}

A total of 233 patients with spinal conditions were included in the study. There were 101 (43.3\%) females and 132 (56.7\%) males giving a F:M ratio of 1:1.1.

The age group of 40-49 years had the highest frequency, constituting $24.9 \%$ of the patients. (Table 1 )

\section{Distribution of Indications in patients}

Out of 233 patients, 54 (23.2\%) patients were evaluated for low back pain, representing the most common condition evaluated. This was followed by $45(19.3 \%)$ patients evaluated for lumbosacral spondylosis and 36 (15.5\%) patients evaluated for paraplegia. (Figure 2) 
Table 1. Demographic variable of patients

\begin{tabular}{lcc}
\hline Variable & Frequency & Percentage (\%) \\
$\begin{array}{l}\text { Gender } \\
\text { Male }\end{array}$ & 132 & 56.7 \\
Female & 101 & 43.3 \\
Total & 233 & 100.0 \\
Age (years) & & \\
$\leq 10$ & 3 & 1.3 \\
$11-19$ & 9 & 3.9 \\
$20-29$ & 17 & 7.3 \\
$30-39$ & 42 & 18.0 \\
$40-49$ & 58 & 24.9 \\
$50-59$ & 48 & 20.6 \\
$60-69$ & 40 & 17.2 \\
$\geq 70$ & 16 & 6.9 \\
Total & 233 & 100.0 \\
\hline
\end{tabular}

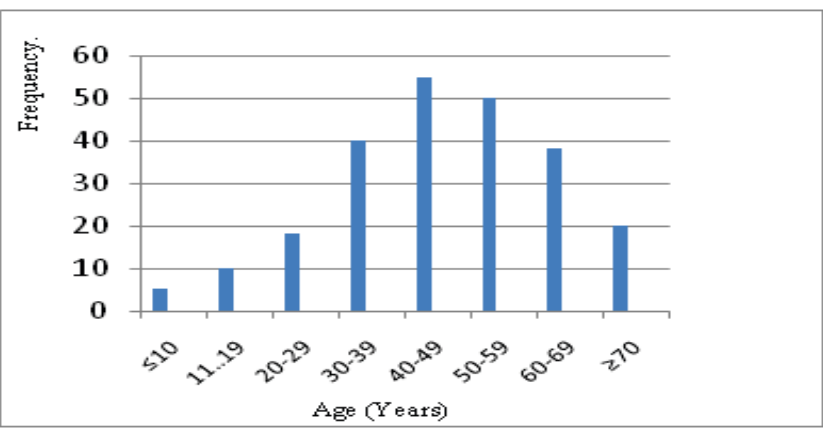

Figure 1: Distribution of patients' age-group

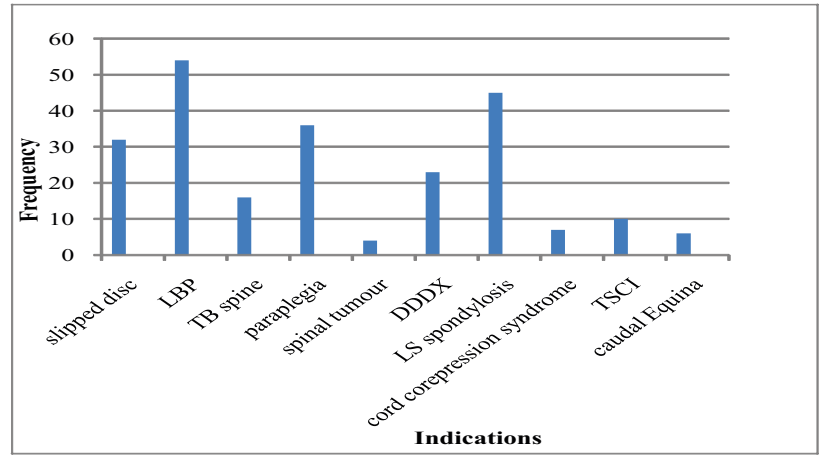

Figure 2: Frequency distribution of indications for MRI in patients.

\section{Distribution of findings in patients}

Degenerative disc disease was found in 89 (38.2\%) patients, accounting for the most common condition in the patients. Degenerative disc disease with exit nerve root was present in $33(14.2 \%)$ patients and lumbarspondylosis in $34(14.6 \%)$ patients. Only 3 (1.3\%) patients had lumber fracture, which represented the least common condition diagnosed (Figure 3)

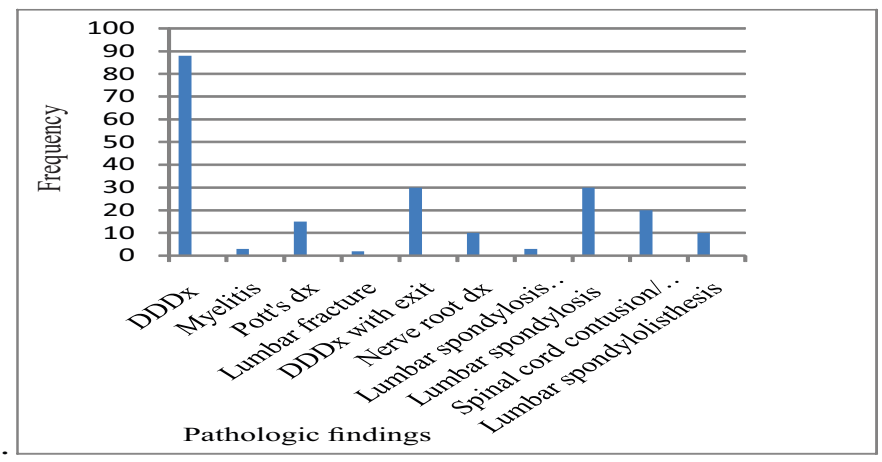

Figure 3: Distribution of pathologic findings in patients

Table 2: Association between age group and indications.

\begin{tabular}{|c|c|c|c|c|c|c|c|}
\hline Age Group & $<20$ & $20-29$ & $30-39$ & $40-49$ & $50-59$ & $60-69$ & $>70$ \\
\hline \multicolumn{8}{|l|}{ Indications } \\
\hline Slipped disc & $0(0.0)$ & $1(5.9)$ & $6(14)$ & $11(19.0)$ & $10(20.8)$ & $2(5.0)$ & $2(12.5)$ \\
\hline Low back pain & $3(25.0)$ & $5(29.4)$ & $6(14.3)$ & $17(29.3)$ & $17(35.4)$ & $6(15.0)$ & $0(0.0)$ \\
\hline TB spine & $1(8.3)$ & $\mathrm{O}(0.0)$ & $0(0.0)$ & $7(12.1)$ & $3(6.3)$ & $3(7.5)$ & $3(12.5)$ \\
\hline Paraplegia & $4(33.3)$ & $7(41.2)$ & $10(23.8)$ & $4(6.9)$ & $5(10.9)$ & $3(7.5)$ & $3(18.8)$ \\
\hline Spinal tumour & $O(0)$ & $1(5.9)$ & $\mathrm{O}(0)$ & $1(1.7)$ & $0(0.0)$ & $2(5.0)$ & $0(0.0)$ \\
\hline Deg. Disc dx & $1(8.3)$ & $1(5.9)$ & $6(14.3)$ & $4(6.9)$ & $1(2.1)$ & $7(17.5)$ & $3(18.8)$ \\
\hline $\begin{array}{l}\text { Lumbosacral } \\
\text { Spondylosis }\end{array}$ & $O(0)$ & $1(5.9)$ & $10(23.8)$ & $9(15.5)$ & $11(22.9)$ & $11(27.5)$ & $3(18.8)$ \\
\hline $\begin{array}{c}\text { Cord } \\
\text { compression } \\
\text { Syndrome }\end{array}$ & $O(0)$ & $O(0)$ & $2(4.8)$ & $2(3.4)$ & $O(0.0)$ & $3(7.5)$ & $0(0.0)$ \\
\hline $\begin{array}{l}\text { Traumatic spinal } \\
\text { Cord injury }\end{array}$ & $3(25.0)$ & $O(0)$ & $2(4.8)$ & $2(3.4)$ & $1(2.1)$ & $0(0.0)$ & $2(12.5)$ \\
\hline Cauda equina & $O(0)$ & $1(5.9)$ & $0(0.0)$ & $1(1.7)$ & $0(0.0)$ & $3(7.5)$ & $1(6.3)$ \\
\hline
\end{tabular}

J Biomed Res. Clin Pract $\mid$ Vol $2 \mid$ No 3 | 2019

For Reprint Contact: jbrcp.net@gmail.com 
Association between age group and indications for MRI.

Out of a total number of 32 patients that had slipped disc as indication in all age groups, $11(19.0 \%)$ represented the highest frequency seen within the 40-49 years age group, followed by $10(20.8 \%)$ seen between the ages of 50 59 years. The highest frequency of TB spine as an indication was seen in 7(12.1\%) patients aged between $40-49$ years. The age group of 60-69 years had the highest frequency of patients with cord compression syndrome as indication, constituting 3(7.5\%). Age groups 30-39 years and 40-49 years had frequencies of $2(4.8 \%)$ and $2(3.4 \%)$ patients respectively (Table 2)

\footnotetext{
Association between gender and pathologies (Table 3 )

The study shows that, from the total of $89(38.2 \%)$ patients that had degenerative disc diseases, males accounted for the highest frequency, constituting $50(37.9 \%)$ patients and females accounted for $39(38.6 \%)$ patients. Out of the $18(7.7 \%)$ patients with Pott's disease, $12(9.1 \%)$ were males and 6(5.6\%) were females. Therefore more males had Pott's disease than females. There was lumbar spondylosis in $34(14.6 \%)$ patients, and more females were affected, (19(18.8\%) females versus $15(11.4 \%)$ males). Spinal cord contusion was found in $28(12.0 \%)$ patients; 15 (11.4\%) of these patients were males and $13(12.9 \%)$ were females.
}

Table 3: Association between gender and lumbar pathologies.
Distribution of gender and indications for MRI Low back pain was indicated in 52 patients in total, which accounted for the most common indication, out of which $35(26.5 \%)$ were males and $19(18.8 \%)$ were females. Similarly, males were in the majority at $23(17.4 \%)$, out of a total of 32 patients who had slipped disc as their indication, while the females were $9(8.9 \%)$. Females accounted for the majority of $4(4.0 \%)$ patients who had cauda equina as indication, while the males were $2(1.5 \%)$. (Figure 4 )

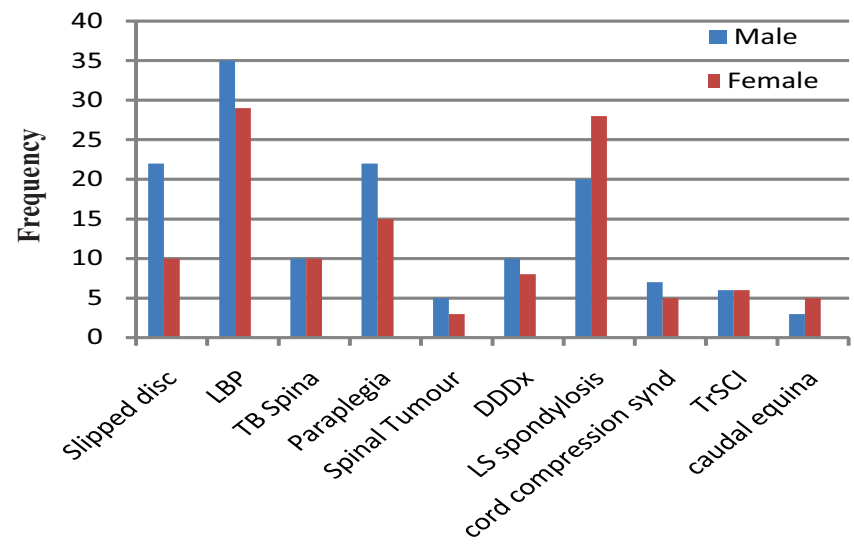

Indication

Figure 4: Association between gender and indications

\begin{tabular}{lccc}
\hline Findings & Male & Female & Total \\
\hline Degenerative disc disease & $50(37.9)$ & $39(38.6)$ & $89(38.2)$ \\
Myelitis & $2(1.5)$ & $2(2.0)$ & $4(1.7)$ \\
Pott's disease & $12(9.1)$ & $6(5.9)$ & $18(7.7)$ \\
Lumbar fracture & $2(1.5)$ & $1(1.0)$ & $3(1.3)$ \\
Degenerative disc disease with exit & $23(17.5)$ & $10(9.9)$ & $33(14.2)$ \\
Nerve root disease & $4(3.0)$ & $1(1.0)$ & $5(2.1)$ \\
Lumbar spondylosis with deg. Disc dx & $2(1.5)$ & $2(2.0)$ & $4(1.7)$ \\
Lumbar spondylosis & $15(11.4)$ & $19(18.8)$ & $34(14.6)$ \\
Spinal cord contusion/Injury & $15(11.4)$ & $13(12.9)$ & $28(12.0)$ \\
Lumbar spondylolisthesis & $7(5.3)$ & $8(7.9)$ & $15(6.4)$ \\
\hline
\end{tabular}


Degenerative disc disease was seen in all age groups, however the highest frequency of 22(37.9\%) was seen between the age of 40-49 years, followed by $20(50.0 \%)$ aged $30-39$ years, The least affected aged group was $\leq 20$ years with $3(25.0 \%)$ patients. Age group 40-49 years had the highest number of patients with Pott's disease i.e. 8(13.8\%). Lumbar fracture was seen in age group 20-29 years with $2(11.8 \%)$ patients and 30 49 years with $1(2.4 \%)$.

\section{Association Between Indications and Findings (Table 5)}

A total of 54 patients had low back pain as an indication, among which 24 had degenerative disc disease, 11 had degenerative disc disease with exit nerve and 10 had lumbar spondylosis.
Out of a total of 16 patients with an indication of TB spine, Pott's disease had the highest finding with 9 patients, of which 3 patients also had degenerative disc disease and 2 patients had lumber spondylosis.

A total of 36 patients had an indication of paraplegia, among which 13 cases were due to spinal cord contusion/injury, 9 had degeneration disc disease and 4 had lumber spondylolisthesis. Degenerative disc disease was an indication for a total of 23 patients, among which 13 had degenerative disc disease, accounting for the majority. In a total of 45 patients with lumbar spondylosis, degenerative disc disease findings accounted for the highest with 18 patients, followed by lumbar spondylosis with 13 patients.

Table 4: Association between age group and findings

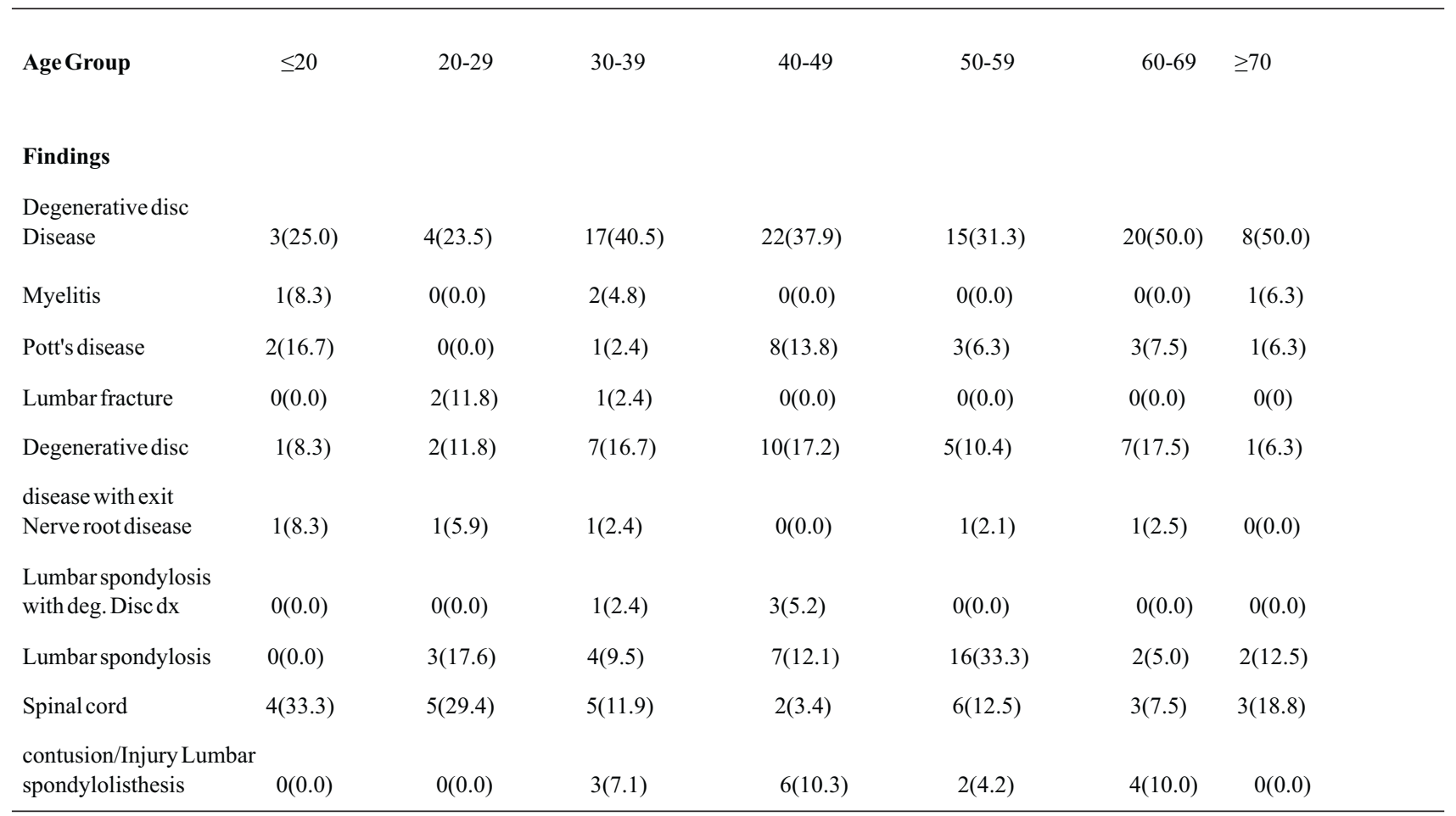

Table 5: Association between findings and indications

\begin{tabular}{|c|c|c|c|c|c|c|c|c|c|c|c|}
\hline \multirow[t]{2}{*}{ Findings } & \multicolumn{6}{|c|}{ Indication } & \multirow[b]{2}{*}{$\begin{array}{l}\text { Lombo } \\
\text { Sacral } \\
\text { spondylosis }\end{array}$} & \multirow[b]{2}{*}{$\begin{array}{l}\text { Cord } \\
\text { Compression } \\
\text { syndrome }\end{array}$} & \multirow[b]{2}{*}{$\begin{array}{l}\text { Traumatic } \\
\text { spinal cord } \\
\text { injury }\end{array}$} & \multirow[b]{2}{*}{$\begin{array}{l}\text { Caudal } \\
\text { equina }\end{array}$} & \multirow[b]{2}{*}{ Total } \\
\hline & $\begin{array}{l}\text { Slipped } \\
\text { disc }\end{array}$ & $\begin{array}{l}\text { Low } \\
\text { Back } \\
\text { pain }\end{array}$ & T B spine & $\begin{array}{l}\text { Para } \\
\text { plagia }\end{array}$ & $\begin{array}{l}\text { Spinal } \\
\text { tumour }\end{array}$ & $\begin{array}{l}\text { Deg. } \\
\text { disc } \mathrm{dx}\end{array}$ & & & & & \\
\hline Degenerative disc disease & 12 & 24 & 3 & 9 & 2 & 13 & 18 & 5 & 1 & 2 & 89 \\
\hline Myelitis & 2 & 1 & 1 & o & 0 & 0 & 0 & o & o & 0 & 4 \\
\hline Potts disease & 1 & 3 & 9 & 2 & 0 & 2 & o & o & 1 & o & I8 \\
\hline Lumbar fracture & $\begin{array}{l}1 \\
0\end{array}$ & 0 & 0 & 2 & 0 & 0 & 0 & 0 & 1 & 0 & 3 \\
\hline $\begin{array}{l}\text { Degenerative disc disease } \\
\text { with exit. }\end{array}$ & 7 & 11 & o & 2 & 0 & 3 & 7 & 1 & 2 & o & 33 \\
\hline Nerve root disease & 1 & 1 & 0 & 2 & 0 & 1 & 0 & 0 & 0 & 0 & 5 \\
\hline $\begin{array}{l}\text { Lumbar spondylosis with } \\
\text { deg. Disc } \mathrm{dx}\end{array}$ & 0 & 0 & o & 0 & 0 & 2 & 2 & 0 & 0 & 0 & 4 \\
\hline Lumbar spondylosis & 4 & 10 & 2 & 2 & 1 & 1 & 13 & o & o & 1 & 34 \\
\hline $\begin{array}{l}\text { Spinal cord / adjacent } \\
\text { injury }\end{array}$ & 3 & 2 & o & 13 & o & 1 & 3 & 0 & 5 & 1 & 28 \\
\hline Lumbar spondylolisthesis & 2 & 2 & 1 & 4 & 1 & 0 & 2 & 1 & o & 2 & 2 \\
\hline Total & 32 & 54 & & & 4 & & 45 & 7 & 10 & 6 & 233 \\
\hline
\end{tabular}




\section{DISCUSSION}

In a study conducted byFredrik Stromqvist et al, at the Department of Orthopedics, Lund University, over 6 years (2000-2005 inclusive) involving 3000 patients (165 males), pre- and post-operative parameters for all patients with lumbosacral spinal conditions were analyzed for sex difference. Statistically significant and clinically relevant sex differences were found. Pre-operatively, females had more pronounced back pain and disability and also lower quality of life (QoL) in some aspects.. At 1 year follow-up, females reported a higher rate of consumption of analgesics, a higher rate of post-operative back and leg pain and less improvement regarding disability and some aspects of QoL. They reported a difference between females and males, as there were more females affected than males. ${ }^{16}$ In contrast, our study indicated that more males had lumbosacral conditions than females.

Low back pain is one of the most common causes of physician visits by patients in the United States, with an enormous socio-economic burden. Because of this burden, numerous lumbosacral MRI(LS MRI) studies have been done to focus on its diagnosis and management. ${ }^{17}$ Since MRI, as a diagnostic tool, has been widely used in Iran, the health system is encountering a high volume of LSMRI request in patients with low back pain. ${ }^{18}$ In our study, 211 (75\%) of MRI requests were consistent with the indications. Different studies show varied results. Some studies show a higher rate of MRI request (Spain $88 \%$ ), while there are studies with similar (USA: 74\% and $78 \%$ ) or lower rate (Canada: $44.3 \%$, Iran: $20.8 \%)^{19}$

In another Iranian study, Saadat showed that $17.2 \%$ of all MRI reports were associated with normal results, with a lower back pain rate of $4.8 \%{ }^{20}$ Suwaid et al reported LS MRI as the commonest MRI in their study, with the commonest indications for the MRI being low back pain and trauma. ${ }^{21}$ These reports are similar to our findings, with low back pain being the most frequent indications for lumbosacral MRI.

According to Mark Hancock, MRI findings including disc degeneration, modic changes and herniation, are more common in selected people with recurrent acute (likely discogenic) low back pain.His previous studies have focused on degenerative disc findings or disc herniation and few have investigated a range of different pathologies on MRI including annular tears, and modic (end plate) changes. ${ }^{22}$ The commonest findings were spondylosis, disc prolapse, compression fracture and spinal metastasis, as seen in the study by Suwaid et al. ${ }^{21}$ These findings are similar to ours, as degenerative disc disease was the most frequent finding and lumbar fracture was the least finding.

Roger $\mathrm{H}$ reported that men have roughly twice the risk for lumbar herniated discs compared with women. ${ }^{23}$ This is similar to our study where more men compared to women had slipped disc.

There are a significant number of reports illustrating gender specific estimates of low back pain. Albatool HAY reported that the prevalence of back pain was greater in females (29.9\%), compared to males (26.8\%), independent of age. ${ }^{24}$ Kofi AK reported a higher prevalence of $56 \%$ among females, while males had $44 \%$ of the total population. ${ }^{25} \mathrm{Low}$ back pain was found in our study to affect both men and women, but more prevalent in women than men.

In a study carried out in South Africa, among the 100 patients with TB spine, females comprised $58 \%$ of cases. The incidence rate was 1.17 per 100,000 females and 0.916 per 100,000 males Godlwana L et al. ${ }^{26}$ We noticed male and female having the same inciden.

In a study comprising 47 new paraplegic patients conducted over a one year period, Equebal et al reported that $37(78.7 \%)$ were males and $10(21.3 \%)$ were females, ${ }^{27}$ which was similar to our findings, where the incidence in men is higher than in women. This is similar to another study, in which there is slight male preponderance for almost all ages was recorded with male: female ratio of $1.26: 1$, according to Abdul R.B. ${ }^{28}$

Teraguchi et al in the Wakayama Spine Study comprising 975 participants (324 males and 651 females) between the ages of 21-97 years. The prevalence of degenerative disc disease was $71 \%$ among the males and $77 \%$ among the females aged $<50$ years, and $>90 \%$ in both men and women aged $>50$ years. The intervertebral space with degenerative disc disease was highest at L4/5 (men 69.1\%, women $75.8 \%$ ). ${ }^{29}$ This is in contrast to our study where males had slightly higher indication than females. A recent Japanese study involving 3040 participants reported the prevalence of lumbar spondylosis to be $80.6 \%$ among males and $64.6 \%$ among females. ${ }^{30}$ The prevalence was noted to increase with age, and was significantly higher among males than females in all areas surveyed in our study.

Cord compression syndrome (CCS)more commonly affects patients aged 50 and older who have sustained a lumbosacral hyper-extension injury secondary to Road traffic accident. It affects males more frequently than females, at a ratio of $3: 1$. It 
is anticipated that the incidence and prevalence of CCS will increase proportionately with an aging population. ${ }^{31} \mathrm{We}$ observed same findings in our study, with males having higher indication.

According to Anda N, their report includes 134 patients with traumatic spinal cord injury. Among these cases, 42 were registered the year 2011, 31 in 2012, 21 in 2013 and 40 in 2014. With respect to sex, $122(84 \%)$ of the 134 patients with TSCI were males and $22(16 \%)$ were females. The male to female ratio was $5: 1 .^{32}$ This is same with our study here, however, there is a slight difference in their percentages, female 5.0 (56.8\%) and male 3.8 (43.2\%). Konstantinou et al reported the prevalence of symptomatic herniated/slipped disc to be about $1-3 \%$, depending on age and sex. ${ }^{33}$ The highest prevalence in this study was found, among patients aged 30 50 years. Our study was different with the highest age group being 40-49 years.

In the patient we studied with slipped disc, about half were aged between 50 - 59 years. Therefore, there is a strong similarity between our study and the study carried out by Jennifer SW et al, which describe the association between back pain related with herniated disc and disability in adults aged 50 years and older. ${ }^{34}$

In Nigeria, the majority of patients with Pott's disease were below the age of 20 years. ${ }^{35}$ In Western countries, the highest incidence is seen in the young adults i.e. ages $20-30$ years. ${ }^{36}$ In Northern Ireland, there was increase in the proportion of adults to children, whereas in Poland, TB Spine was observed to be a disease that predominantly affects old people above 60 years of age. ${ }^{37}$ Generally, TB Spine was found in the age group 45 - 54 years in 12 patients $(24 \%) .{ }^{38}$ According to a study carried out in 72 patients by Bashir GEA et al, the highest incidence of TB spine was seen in age group $41-56$ years andthe age group 55-64 years were least affected in a study. ${ }^{39}$ It showed that the age group with the highest indication in the study we conducted is $40-49$ years.

Development of paraplegia in both males and females is bimodal. Males are more at risk in young adulthood (20-29 years) and older age (above 70 years). Females are most at risk in adolescence (15-19 years) and older age (above 60 years). ${ }^{40}$ In another study in Minnesota, USA, the age of peak incidence was typically between 15-30 years of age and over 70 years for both sexes. An exception to this was South East Turkey, where the peak incidence occurred in the 40 - 49 years age group. ${ }^{41}$ We observed paraplegia more in the age group of 30 39 years, which is different from the previous studies stated earlier.

Depending on the age of the patient and the type of spinal tumor; in adults, the mean age of occurrence is between 35-40 years while in children, the mean age of occurrence is between 5-10 years. ${ }^{42}$ We found more spinal tumours in the age group of 60-69 years, which is higher than in the previous study.

Powel et al had 302 women with no history of back pain undergo MRI of the lumbar spine. More than a third of the women aged 18-40 years had at least one degenerating disc. ${ }^{43}$ The percentage was however highest for those older than 40 years of age in our study.

In the United States, more than $80 \%$ of individuals older than 40years have lumbosacral spondylosis, increasing from $3 \%$ of individuals aged 20-29 years. Approximately 30\% of men and 28\% of women aged 55-64 years have lumbar spondylosis. In another study conducted simultaneously by Bruce MR et al, approximately $20 \%$ of men and $22 \%$ of women aged 45-64 years have lumbosacral spondylosis. Internationally, lumber spondylosis can begin in persons as young as 20 years. It increases with, and perhaps is an inevitable concomitant of age. ${ }^{44}$ Our study was quite different as the highest age group was 60-69 years.

Cauda equina syndrome, CES occurs primarily in adults, although trauma-related CES can affect people of all ages. According to a study conducted in 2018, patients with CES had a mean age of $44.16 \pm 12.83$ years, ranging from 22 to 64 years. ${ }^{45}$ We observed that the age group of 60-69 years have the highest incidence in our study. Regarding degenerative disc disease, West et $\mathrm{al}^{46}$ found out thatgender did not affect the presence or the extent of the disease. Compared to our study, females showed a marginally increased tendency to have degenerative disc disease.

Dorlan et al carried out a retrospective cohort study of 192 patients initially presenting with myelitis of unknown etiology, which showed that sex and races for adults and children are equally affected. ${ }^{47}$ We noted equal affectation in both sexes in our study, and more among the age group of 3039 years. Kudlacek reported a higher prevalence of lumbar fracture in the male population. ${ }^{48}$ This is similar to our study. According to the AHRQ's 2010 National statistic of lumbar radiculopathy, females are affected more frequently than males and accounts for $53.69 \%$ of cases and the most affected age group is between 45 and 64 years with $51.03 \%$ of incidents. $^{49}$

Our study showed that males have more nerve root disease. 
Contrary to our study findings, Ali et al reported that nerve root disease was more prevalent in women than in men. ${ }^{50}$ Most recent studies agree to the fact that lumbar spondylosis was more prevalent and more severe in men whereas Degenerative Disc disease was more prevalent in women. ${ }^{51}$ we noticed equal prevalence among males and females. Lawrence reported that males were approximately four times more likely to have spinal cord contusion than females. Overall, males accounted for $80.7 \%$ of reported injuries/contusion of the spinal cord. ${ }^{52}$ There is a slight increase in males compared to females in our study.

The male/female ratio of lumber spondylolisthesis prevalence was 1:1.3 in the elderly. ${ }^{53}$ Lai-chang et al reported that men were more likely to have retrolisthesis. ${ }^{53}$ Females were noted with more lumbar spondylolisthesis compared to males in our study, which is quite different from the previous study. A small study group of 64 women, aged 20-29 years, with a mean age of 21.3 years were shown to have a Degenerative Disc disease. Two (4.8\%) patients aged 30-39 years had myelitis, which accounted for the highest frequency, while both extremes of ages $(\leq 20$ and $\geq 70$ years of age) had the lowest frequency of $1(8.3 \%)$ and $1(6.3 \%)$ respectively. ${ }^{54}$ The peak incidence rates are bimodal, occurring between 10-19 years and 30-39 years. ${ }^{54}$ This is different to our study findings, where the highest incidence was seen in the age group of 40-49 years. In a study of 100 patients with Pott's disease, Elwathiq et al reported that it was more frequent in the age group of 45-54 years. ${ }^{55}$ It occurred earlier in our study, in which is commonest in the age group of 40-49 years. Degenerative disc disease is an age related condition that can often be the underlying cause of bulging/slipped discs. Over time, and with years of pressure from weight and movement, the discs become less flexible and lose water content leading to degeneration. ${ }^{56}$ However, more advanced degeneration, diagnosed as degenerative disc disease can lead to displacement of the disc through bulging or herniation that causes painful nerve compression. ${ }^{56}$ Ong et al reported that degenerative disc disease was more common compared to other pathologies. ${ }^{56}$ This is similar to what was found in this study.

Brinjikji et al, in a meta-analysis, demonstrated MRI evidence of degenerative disc disease being more common in adults with low back pain, compared to asymptomatic individuals. ${ }^{57}$ Similar findings was observed in our study. In a study conducted by Ravindra et al, MRI results revealed an involvement of the vertebral bodies, disc destruction, vertebral collapse and spinal deformity. In the early stages, however, only disc degeneration with alteration of bone marrow signal intensity of vertebra was seen, which may not be sufficient findings to diagnose TB spine. ${ }^{58}$ Similar findings noted in this study.

The most common cause of spinal cord trauma is automotive accident, which corresponds to more than half of the cases of paraplegia. ${ }^{59}$ The most common spinal cord injury region is cervical region, present in $50-64 \%$ of patients, while the lumbar region represents $20-24 \%$ of the cases of paraplegia. ${ }^{59}$ Spinal cord injury was the most common cause of paraplegia in our study. Spinal tumour can be seen involving osseous, extra-osseous, marrow infiltration, epidural, nerve and the cord. ${ }^{60}$ Increase in the growth of the spinal tumour can cause impingement on the neural element and theca sac, as well as the spinal cord. ${ }^{60}$ It is commonly seen involving the bones in our study.

Suther et al diagnosed and studied a total of 109 patients with lumbar disc degeneration, aged between 17 and 80 years, using 1.5 Tesla MRI machine. ${ }^{61}$ Findings like lumbar lordosis, Schmorl's nodes, decreased disc height, disc annular tear, disc herniation, disc bulge, disc protrusion and disc extrusion were observed. Narrowing of the spinal canal, lateral recess and neural foramen with compression of nerve roots were also observed. ${ }^{61}$ MRI can also be used to visualize the vertebrae, the facet joints, the nerves, and the ligaments in the spine and nerve compression, said Dries M. ${ }^{62}$ The visualized intervertebral disc shows some degree of disc herniation. The articular joints were not clearly visualized because of the low strength MRI used in our study. Similar to this study, Saleem et al reported an obvious severe multilevel lumbar degenerative disc disease and spinal cord compression in the extension posture, and may present as disc herniation, lumbar spinal stenosis, facet joint arthropathy or any combination, accounting for a higher prevalence compared to other findings. $^{63}$

MRI with superior tissue characterisation provides the best evaluation of soft tissue pathology and is essentially the only direct evaluation of the spinal cord and nerve roots. ${ }^{64}$ Several types of traumatic spinal cord lesions can be identified, including intramedullary haemorrhage, spinal cord contusion/oedema, extrinsic compression by a bone fragment or a traumatic disc herniation and even complete transection of the cord. Sarita M et al, ${ }^{64}$ as noted in our study.

MRI with and without contrast provides a detailed look at 
tumors, infection, degenerative intervertebral disc disease and nerve root disease. ${ }^{65}$ It determines if the nerves are being compressed, to what degree and by what structures, ${ }^{65}$ as noted in our study. MRI has helped us tremendously in making diagnosis in patients that presented with low back pain which is due to conditions involving the lumbosacral region

\section{Conflict of Interest}

None declared.

\section{REFERENCES}

1. John MB, and Albany NY. Painful conditions in the lumbar, Lumbosacral and sacro-iliac regions. Arch Surg. 2005;11 (6):883 - 910 .

2. Michael Thomas. Orthopaedic and laser spine surgery: Herniated disc. Available from: https://www.orthopedicandlaserspinesurgery.com. \{ACCESSED ON 19/5/2018\}

3. Galukande M, Muwazi S, Mugisa D. Aetiology of low back pain in Mulago Hospital Uganda. African Health Sciences 2005; 5(2): 164-7.

4. Omokhodion FO. Low back pain in an urban population in South-West Nigeria.Tropical Doctor 2004; 34:17-20.

5. Järvinen J, Karppinen J, Niinimäki J. Association between lumbar Modic changes and low back symptoms over a two -year period. BMC Musculoskeletal Disorders 2015; 16: 98.

6. Shah V, Salam H. Pott's Disease. [cited 2018 March 1]. Available from: https:// www.radiopaedia.org.

7. Neurosurgery and spine surgery. www.apollohospitals.com/patient care/health and life style/disease and condition/paraplegia. \{ACCESSED ON $2^{\mathrm{ND}}$ MARCH, 2018\}.

8. Spinal tumours; paediatrics Spinal tumours. wWw.AANS.org/patient/ neurosurgical conditions and treatments/spinal tumours. $\left\{A C C E S S E D\right.$ ON $2^{\mathrm{ND}}$ MARCH, 2018?

9. Peter F, Ullrich J. Lumber degeneratative disc disease.2013. Available from:www.spinehealth.com \{ACCESSED ON 10/7/2018\}

10. Litao A, Craig CY. Lumbosacral spondylosis in sport medicine 2015.Available from: wWw.medscape.com \{ACCESSED ON 5/6/2018\}

11. Spinal cord compression.Available from: www.columbianeurology.org./neurology/staywel/doc ument.php?id=41939 $\left\{\right.$ ACCESSED ON $2^{\mathrm{ND}} \mathrm{MARCH}$, $\underline{2018\}}$

12. Lawrence SC, Brain HK. Spinal cord injury in emergency medicine.Available from:https://emedicine.medscape.com/spinal-cordinjuries. 2017 August 10. \{ACCESSED ON 20 OCTOBER, 2018\}
13. Spinal cord injury.Available from: https://mayoclinic.org \{ACCESSED ON 4/4/2018\}

14. Christopher SA, Satoshi N, Lindsay T, Jefferson W, Brain K, James H et al. Traumatic S.C.I repair and regeneration. Neurosurgery, 2017: 80 (35): S9 -S22.

15. Cauda Equina Syndrome overview: Available from: https://www.webmed.com \{ACCESSED ON 29/5/2018?

16. Stromqvist F, Ahmad M, Hildingsson C, Jonsson B, Stromqvist B. Gender difference in lumbar disc herniation surgery.Journal ActaOrthopaedica. 2008; 79 (5): 643-49.

17. Roudsari B, Jarvik JG. Lumbar Spine MRI: Indication and yield. Best practice review. American Journal of Roentgenology 2010; 195 (3): 550-52.

18. Mohammedi N, Farahmand F, Kharazi HH. Appropriateness of physician's lumbosacral MRI requests in private and public centres in Tehran, Iran Med J. Islam Repub.Iran.2016; 30:415.

19. Navid M, Ferial F, Marzieh N and Hossein MAppropriateness of physician's lumbosacral MRI requests in private and public centres in Tehran, Iran. Med J. Islam Repub.Iran.2016 (17 sept). vol 30:415

20. Saadat S, Ghodsi SM, Firouznia K, Elminan M, Goudarzik M. and Naieni KH. Overuse or underuse of MRI scanners in private radiology centers in Tehran. Int J Technol Assess health care. 2008 summer;24(3):277 - 81

21. Suwaid MA, Ismail A, Idris MM. Spectrum of spinal abnormalities on MRI of patients with clinical suspicion of spinal lesions in Kano, Nigeria. Journal of the West African College of Surgeons. 2014; 4(4): 2738.

22. Hancock M, Maher C, Pik J. MRI findings are more common in selected patients with acute low back pain than controls. Eur Spine J. 2012; 21(2):240-46.

23. Roger H. Lumbar herniated disc: Causes and risk factors.Available from: www.spirehealth.com \{ACCESSED ON 15/12/2018\}

24. Albatool HA. Gender differences in low back pain and self-reported muscle strengthening activity among US adults. UNF digital commons 2015; 1: 4-5

25. Kofi AK, William KA, Samuel YO, Lawrence A.The prevalence of low back pain on patients'radiological reports.European Journal of Research in Medical Sciences. 2015; 3(3):2015.

26. Godlwana L.Incidence and profile of spinal tuberculosis in patients at the only public hospital admitting such patients in Kwazulu- Natal. Spinal cord. 2008; 46(5): 372-4.

27. Equebal A, Anwer S, Kumar R. The prevalence and impact of age and gender on rehabilitation outcome in spinal injury in India: A retrospective pilot study. Spinal cord 2013; 51: 409-12.

28. Abdul RB, Altat RK, Mohammed AW, Mohammed HB. Incidence, histopathology and surgical outcome of tumours of spinal cord, nerve roots, meninges and vertebra column - Data based on single institutional 
experience J. Neorosci Rural practice 2016; 7(3): 38191 .

29. Teraguchi M, Yoshimura N, Hashizumet H. Prevalence and distribution of intervertebral disc degeneration over the entire spine in a population-based cohort: The Wakayama spine study, 2014; 22(1): 104-110.

30. Sung YL, Nam H. Cho et al. Prevalence and risk factors for lumbar spondylosis and its association with LBP among rural Korean Residents. J. Korean Neurosurg Soc. 2017;60(1): 67-74.

31. Rumaiza A, Yazid M, Hassan M. Spinal cord compression secondary to idiopathic thoracic epidural lipomatosis in an adolescent: A case report and review of literature.International Journal of Surgery case reports.2017; 37: 225-29.

32. Anda N, Uljana T, Anita V. A profile of traumatic spinal cord injury and Medical complication in Latvia. Spinal cord Ser Cases, 2017;3:17088.

33. Konstantinou K. Herniated slipped disc. Jordan Research Information manager www.ncbi.nlm.nih.gov/pmc/articles. \{ACCESSED ON 12/11/2017?

34. Williams JS. Risk factors and disability associated with low back pain in older adults in low and middle income countries. Results from the WHO study on Global Ageing and Adult Health (SAGE). PLoSONE2015;10(6): e0127880.

35. Odey F, Umoh U, Meremikwu M, Udosen A. potts disease in children and Adulescents in calabar, Nigeria. The internet Journal of infectious disease. 2006 vol. 6, number 1 .

36. Ravindra KG andDilip SS. Spinal tuberculosis: A review. The journal of spinal cord medicine. 2011 sept;34 (5) 440-454.

37. Hodgson Ar. Report on findings and results in 300 cases of pott's disease treated by anterior fusion of the spine. J wesr pacific orthop Ass 2001; 1:3

38. Mortin NS. Tuberculosis of the spine: A study of the result of treatment during the last twenty five years. J bone joint Surg 2007, 523-613

39. El Bashir GUSM,Ahmed E, Eldin TOS. Clinical pattern of Pott's disease of spine, outcome of treatment and prognosis in adult Sudanese patients.Factsheets: spinal cord injury, 2007;7:28-4

40. Available from: www.who.int/mediacentre/newsroom/fact-sheets/detail/spinal-cord-injury 19 November 2013. [ACCESSED ON 26/2/2018]

41. Anoushka S, Lindsay T, Micheal GF. Global prevalence and incidence of traumatic spinal cord injury. Chemical Epidennology. Available from: www.ncbi.n/m.gov [ACCESSED ON 23/1/2018]

42. Alfred TO, Brain HK, Thomas LF. Intramedullary spinal cord tumors.[cited...]. Available from: https:// emedical.medcape.com

43. Powell MC, Szypryt P, Wilson M, Symonds EM, Worthingtor BS. Prevalence of lumber disc degeneration observed by magnetic resonance in symptomless women. Lancet, 328, 1366-1367.
44. Bruce MR, Brain HK. Lumber spondylosis. Available from: https://emedicine.medscape.com \{ACCESSED ON $5^{\text {TH }}$ JUNE 2018.

45. Andre LND, Olavo BL, Fernando FDA, Alexandre FC. Epidemiological study of caudaequina syndrome, what happened until 2015.Revista Brasileira de Ortopedia, English edition, 2018; 53(1):107-112.

46. West W, West KP, Younger EN, Corwall D. Degenerative disc disease of the lumbar spine on MRI. Pubmed West Indian Med J. 2010; 59(2): 192-5.

47. Dorlan JK, Maureen AM, Alexandra S, and Michael L. predictors of recurrence following an initial episode of transverse myelities. Neurol Neuroimmunol.

Neuroinflam 2014 june; 1(1):e4 published online 2004, Apr 24.

48. Kudlacek S, Schneider B, Resch H, Freudenthaler O. Gender difference in fracture risk and bone mineral density. Maturitas 2000;36 (3): 173-80.

49. Tarulli AW, Raynor EM ( may 2007). Lumbosacral Radiculopathy. Neurolohic Clinics. 25 (2):387-405

50. Ali MA. Prevalence of spinal disorders and their relationship with age and gender. Saudi Med. 2015; 36(6):725-30.

51. Adam PA, Timothy SC, Joanne MJ. Low back pain and lumbar spine osteoarthritis: How are they related? Curr Rheumatol Rep. 2013; 15(2): 305.

52. Lawrence SC, Fassil BM, Segun TD. Spinal cord injuries. Available from: https://emedicine.medscope.com \{ACCESSED ON 26/08/2018\}

53. Lai-chang HE, Yi-xiang JW, Jing-shan G, James FG.Prevalence and risk factors of lumbar spondylolisthesis in elderly Chinese men and women. Eur Radio 2014; 24 (2) 441-48.

54. Transverse myelitis. fact sheet (2017) NINDS, publication No:17 4841

55. Elwathiq KI, Elbashir GE, Nour EE, MamounMM. Vertebral distribution of Pott's disease on the spinal cord among adult Sudanese patients in Khartoum, Sudan. American Journal of Health Research 2014; 2 (3): 93-106.

56. Ong A, Anderson J, Roche J. A pilot study of the prevalence of lumbar disc degeneration in elite athletes with lower back pain at the Sydney 2000 Olympic Games. British Journal of Sports Medicine 2018; 37 (3):3,73,263.

57. Brinjikji OR, Diehn FE, Jarvile JG, Carr CM,Kallmes DF. MRI findings of disc degeneration are more prevalent in adults with low back pain, than in asymptomatic controls: A systematic review and metaanalysis. Am J Neuwradial 2016; 36(12): 2394-9.

58. Ravinda KA, Dilip SS. Spinal Tuberculosis: A review. Journal of Spinal Cord Medicine, 2011; 34(5) 44-454.

59. Alex PA, Alberto AT, Alberto CJ, Ciro JP, Giovanna ISM. Chemical assessment and magnetic resonance imaging of the shoulder of the patients with spinal cord injury. Acta Ortop Bras.2012; 20(5): 291-96. 
60. Ravi N, Manjappa BNH, Nagaraj BR, Nwveen KG.

MRI Evaluation of different spectrum of spinal tumors. SSRG-IJMS 2014;1(2):18

61. Suther P, Patel R, Mehta C, Patel N. MRI evaluation of lumbar discdegenerative disease J. Clindaign Res.2015; a (4) 34-31.

62. Dries M, Robins P, Mathias P, Kevin R, Mame A.

Lumbar spondylosis. Available

from:http://www.physiopedia.com \{ACCESSED ON $\underline{14 / 11 / 18\}}$

63. Saleem S, Rehmani MAK, Raees A, Arsalan A, Ashraf J. Lumbar disc degenerative disease: Disc degeneration symptoms and magnetic resonance Imaging findings. PubMed Central. Published on 01/01/13.

64. Sarita M, Deepak S, Rohtas KY, Manju B. Evaluation of traumatic spine by magnetic resonance imaging and correlation with neurological recovery. Asian Spine J, 2015; 9(5): 748-58.

65. Jason C, Melissa CS. CaudaEquina Syndrome. Available from:www.emedicinehealth.com $\{$ ACCESSED ON 15/06/2018\}. 